\title{
The application of strength-based positive psychology program for elite archers
}

\author{
Youngsook Kim \& Inchon Park*
}

Korea Institute of Sport Science

\begin{abstract}
[Purpose] The goal of this study was to investigate the application effect of strength-based positive psychology intervention to elite archers. [Methods] Total of 20 elite archers participated in this study. Treatment group consisted of 10 elite archers participated in the strength-based positive psychology intervention for 8 weeks. Each individual responded the questionnaires in pre- and post-treatment sessions. Data were analyzed by repeated-measure ANOVA. Furthermore, archers participated in the program responded to in-depth interviews. [Results] According to the results, participants in strength-based positive psychology intervention showed that significantly increased strength knowledge, strength use, and optimism in the post - treatment compared to the pre-treatment session while control group did not show significant changes. In addition, archers perceived that there were positive effect on thinking coping and their self-confidence and self-esteem enhanced after participating the program. [Conclusion] The results of this study suggested that strength-based positive psychology intervention has positive impact on athlete's wellbeing and perception of individuals strength and can be applicable to different sports field.
\end{abstract}

Key words: archery, strength-based, positive psychology, strength knowledge, strength use

\section{서 론}

긍정심리 분야는 초기 전통 심리학의 병리학적, 심리 적 약점 중심의 연구 추세와 반대로 인간의 강점을 강조 하고자 하는 움직임으로 발달하게 되었다(Linley, Joseph, Harrington, \& Wood, 2006; Seligman \& Csikszentmihalyi, 2014). 긍정심리학은 인간이 무엇을 잘 못하고 있는지 보다 어떻게 인류가 더 탁월해 질 수 있 을까에 대한 질문에 해답을 찾기 위한 학문이다 (Compton, 2005). 이러한 관점은 긍정심리학을 통해 인 간의 긍정적 감정 구축과 증진을 위한 연구를 진행한 Cravens 등(2010)에 의해 널리 받아들여지기 시작했다.

논문 투고일 : 2020. 07. 08 .

논문 수정일 : 2020. 08. 24.

게재 확정일 : 2020. 09. 11.

* 교신저자 : 박인천(pic2pac@gmail.com).
강점-기반 접근은 최근 이런 심리학의 학문적 시류의 한 부 분으로 형성되었다. 이런 강점-기반 접근 개념은 개인의 최 상수행 달성을 위해 개인의 긍정적 특징을 발견하고 강조하 는 발달적 (developmental) 접근을 시도한 Buckingham과 Clifton(2001)에 의해 최초로 소개되었다.

스포츠 현장에서 강점-기반 접근은 재능 있는 유망주 를 양성하고 긍정적인 결과를 이끌어내고자 하는 목적으 로 오랫동안 사용되어왔다(Noble et al., 2000). 사실 스 포츠에서 개인의 최고 성적과 높은 성취도는 심리적 개입 과 아주 밀접하게 관련되어 있기 때문에 심리학적 관점에 서 선수의 성장에 영향을 주는 접근법을 특정하기엔 논란 이 있다(Sarkar \& Fletcher, 2013). 강점-기반 접근은 선수들이 최적의 상태로 최상 수행에 집중할 수 있도록 유용한 플랫폼을 제공하는데 그 목적이 있다(Kaiser \& White, 2009). 이 접근은 개인의 가용자원을 최적으로 사용할 수 있도록 하며 자신이 가진 능력을 바람직한 최 
종 결과로 이어질 수 있도록 도와준다(Stander et al., 2014). 따라서 강점-기반 접근은 선수의 장점과 잠재력 에 초점을 둔다(Linley et al., 2006).

스포츠심리학에서 전문가들이 주로 채택하는 지배적 인 상담기법으로 인지행동기법(cognitive behavioral therapy; CBT)이 있다(Sharp, Hodge, \& Danish, 2014). 인지행동기법의 주요한 초점은 부정적 사고장애 를 치유하고 이러한 장애를 극복하기 위한 일련의 장치를 개발하는 문제-중심적 접근방식에 기초한다(Scheel, Davis, \& Henderson, 2012). 인지행동기법이 스포츠 심리학자들에게 미친 지배적 영향으로 인해 아직도 일부 선수들과 지도자들은 스포츠심리학이 문제를 안고 있는 선수들을 지원해주는 분야라고 생각하고 있다. 더욱이 스 포츠심리학자들이 선수들의 요구를 측정할 때 가장 일반 적으로 사용하는 방법으로 수행 프로파일(Butler \& Hardy, 1992)이라는 점은 이러한 한계를 잘 보여준다. 이 과정에서 강점과 약점을 모두 확인할 수 있지만, 중재 초기 단계에서 훈련의 목표는 주로 선수의 약점을 보완하 는 것으로 시작된다(Weston, Greenlees, \& Thelwell, 2011, 2013). 일반적으로 스포츠에서는 선수의 약점을 잘 극복해야 경기력을 향상 시킬 수 있다는 생각이 지배 적이고 강점을 발달시키기 보다는 약점을 최소화하는데 초점을 맞춘 훈련을 설계한다(Gordon, 2012). 이는 스 포츠심리학자가 강점-기반 접근을 적용하는데 실패했다 는 것을 의미하지는 않지만, 관련 연구에서 이러한 논쟁 을 종식시킬만한 증거를 찾기 힘들다(Ludlam, Butt, Bawden, Lindsay, \& Maynard, 2016).

최근 운동선수들을 대상으로 강점-기반 접근에 초점을 맞춘 다양한 중재방안의 개발과 활용에 대한 연구에서 긍 정적인 결과들이 보고되고 있다. 북미 올림픽 대표 선수 들을 대상으로 한 연구에서 불안 조절 능력, 정신력, 자신 감, 스포츠 지능과 같은 특성들이 강점으로 나타났으며, 워크숍이나 중재를 통해 선수들의 심리적 강점을 높이는 과정은 경쟁에서 성공을 예측하는 중요한 변인이라 보고 했다(Gould et al., 2002). 또한 영국 프로 럭비선수들을 대상으로 강점-기반 심리 기술 훈련을 적용한 결과 정신 력과 인내심이 신장된 것으로 나타났으며 이는 이후 수행 향상으로 이어지는 결과를 나타냈다고 보고했다(Golby $\&$ Sheard, 2004). 흥미로운 점은 크리켓과 같은 팀 스
포츠에서 개인 또는 소그룹 훈련 시 강점-기반 코칭의 적 용을 통해 개인 수준의 강점을 강조한 결과 팀의 수행력 에 긍정적 영향을 준다는 것을 확인하였다(Gordon, 2012). 이러한 결과는 대표적인 팀 스포츠 종목인 럭비 에서도 확인되었는데, 개인의 강점활용은 운동열의 (athlete engagement)의 예측변인(predictor)로써 팀 수준의 강점활용과 운동열의 관계를 매개하는 변인으로 작용하는 것으로 밝혀졌다(Stander, Mostert, \& De Beer, 2014). 다수의 사전 연구에서 심리적 강인성을 증 진시키기 위한 방법으로 강점-기반 접근법을 채택하여 긍정적 결과를 도출하였지만, 이 기법 자체의 역할과 영 향력에 대한 심도 있는 고찰은 이루어지지 않았다. 그러 나 강점-기반 중재기법 적용 후 진행된 심층면담에서 선 수들은 자신의 강점에 대해 논의할 수 있는 기회가 있어 서 좋았다고 보고했으며 스포츠심리학에서 강점-기반 접 근의 긍정적 활용과 고찰을 위한 추가적인 후속연구의 필 요성을 시사한다(Gould et al., 2002; Gordon, 2012).

한편, 양궁 종목은 경기력에서 체력·기술·심리·전술 중 심리 요인이 차지하는 중요도가 $51.9 \%$ 에 달하는 것으로 나타났다(Yun, Kim \& Lim, 2006). 지금까지 양궁선수 들을 대상으로 한 연구 또한 양궁 기술에 대한 체력적, 역 학적, 기술적 연구보다는 선수들의 자기관리(Moon \& Park, 2008), 정서조절 (Kim \& Oh, 2015 ), 심상(Lee, Kim \& Kim, 2009), 자신감(Moon \& Park, 2008) 등 과 같은 심리적 요인에 집중되어왔다. 양궁선수의 최상 수행을 위한 심리기술 훈련의 현장적용은 중학생 (Choi \& Song, 2017), 실업팀(Han, 2012), 국가대표(Kim \& Yang, 2010) 등 다양한 대상을 중심으로 연구가 진행되 어왔다. 이 연구들은 공통적으로 운동수행에서 중요한 역 할을 하는 불안, 자신감, 심상조절능력, 주의 집중과 같은 심리적 요인들을 중심으로 훈련을 구성하고 평가함으로 써 수행의 일관성을 높이는(Choi \& Song, 2017) 등 심 리기술 훈련 및 상담의 효과를 검증해왔다. 하지만 기존 의 훈련 및 상담 방식은 서두에 언급했던 것과 같이 문제중심적 접근방식에 기초한 인지행동치료라는 틀을 벗어 나지 못하고 있다. 또한, 전통적 훈련 및 상담 방식에서 선수들은 능동적 주체라기보다 전문가가 제공하는 프로 그램과 정보를 일방적으로 수용하는 수동적 객체로 참여 하게 된다. 전통적 방식과 달리 강점-기반 접근법은 내담 
자가 자신의 문제점 보다는 강점과 같은 긍정적 특성에 집중하게 되고 자신의 강점을 스스로 탐구하는 과정을 통 해 성장하고 어려움을 극복해 나간다는 점에서 기존의 중 재기법과는 차이가 있다.

본 연구에서는 강점 기반 긍정심리 관련 선행연구를 기반으로 개발된 강점-기반 긍정심리프로그램을 현장에 적용하고 그 효과를 검증하는데 목적이 있다. 강점-기반 긍정심리학 연구는 국·내외를 막론하고 활발히 진행되고 있으나 그 대상이 병동에 있는 외상환자(Laschinger \& Fida, 2014), 작업현장의 육체노동자(Ouweneel, Le Blanc, \& Schaufeli, 2013), 학습 환경에 있는 일반 대학 생 (Bolier et al., 2013) 또는 우울증이나 ADHA와 같은 정서적·정신적 장애를 가진 환자(Layous, Chancellor, Lyubomirsky, Wang, \& Doraiswamy, 2011)에 제한되 어있다. 따라서 과도한 스트레스와 압박감을 경험하게 되 는 스포츠 현장에 있는 운동선수들을 대상으로 한 연구는 아직 부족하다고 판단된다. 본 연구에서는 선행 연구들을 토대로 개발된 심리프로그램이 선수들에게 미치는 영향 과 강점-기반 접근의 역할을 설문지와 심층면담을 통해 탐구하고자 한다. 또한 이렇게 검증된 강점-기반 긍정심 리프로그램을 다른 종목의 운동선수들에게 적용한다면 경기력 향상에 도움을 줄 수 있을 것으로 예상된다.

\section{연구방법}

본 연구는 강점-기반 긍정심리프로그램을 현장에 적용 하고 그 효과를 검증하기 위하여 현직 양궁 선수 20 명을 대상으로 프로그램 적용집단과 통제집단으로 배치하여 프로그램 적용 사전과 사후의 심리 변화를 알아보았다.

\section{연구참여자}

본 연구에서는 연구참여자 선정과정에서 연구책임자 가 대한양궁협회 사무국과 접촉하여 연구의 목적과 내용 에 대해 설명한 후 동의를 득하고, 연구참가에 동의한 양 궁 실업팀 선수 20 명을 대상으로 하였다. 프로그램 적용 집단의 경우 사전에 8주 간의 강점-기반 긍정심리프로그 램에 대한 설명 후 참가에 동의한 양궁선수 10 명을 대상
으로 하였으며, 통제집단은 실업팀에 소속된 양궁 선수 10 명으로 구성되었다. 프로그램 적용집단과 통제집단 선 수들 모두 긍정심리프로그램에 대한 교육이나 중재를 받 은 경험이 없는 것으로 파악되었다. 모든 참여자는 연구 자로부터 프로그램, 설문 및 프로그램 적용에 대한 기본 정보와 목적에 대한 설명을 듣고 이해하도록 하였으며, 기관 연구윤리위원회의 승인을 받은 연구동의서에 서명 을 하고 연구에 참여하도록 하였다.

\section{조사도구}

1) 강점인식

이 연구에서는 양궁선수들의 강점인식을 측정하기 위 한 강점인식 척도로 Govindji와 Linley(2007)가 개발한 8개의 문항으로 구성된 강점인식 척도(Strength Knowledge Scale)를 번역하여 사용하였다. 척도의 내용 은 응답자들에게 자신의 강점을 어느 정도 인식하는지 묻 는 질문으로 7점 척도를 사용하여 최소 8점 (전혀 아니다) 에서 최대 56점(매우 그렇다)으로 평가하도록 되어있으 며 총 8문항으로 구성되어 있다. 구체적으로 문항은 "내 강점을 인식하고 있다, 내가 무엇을 잘하는지 알고 있다, 내 강점을 잘 알고 있다, 내가 가장 잘 하는 것을 알고 있 다" 등의 내용으로 구성되어 있으며, 내적 신뢰도는 .89 로 나타났다.

\section{2) 강점활용}

이 연구에서는 양궁선수들의 강점활용을 측정하기 위 하여 Park과 Lee(2012)가 Govindji와 Linley (2007)의 연구에서 사용된 강점활용 척도(Strength Use Scale)를 번역하여 사용한 한국판 강점활용 척도를 이용하였다. 총 14 개 문항으로 구성되며 7점 척도로 점수가 높을수록 자 신의 강점을 많이 활용하는 것을 의미한다. 문항의 예시 로는 "나는 항상 나의 강점을 발휘한다, 나는 매일 나의 강점을 활용한다, 나는 내가 하는 일에서 강점을 쉽게 활 용하는 편이다"등의 내용으로 구성되어 있으며, 내적 신 뢰도는 .95로 나타났다.

3) 낙관성(삶의 지향성)

이 연구에서는 양궁선수들의 낙관성을 측정하기 위한 
Table 1. Contents of strength based positive psychology program.

\begin{tabular}{|c|c|c|c|c|c|}
\hline Goal & week & Context & Activities and contents & Outcomes & related articles \\
\hline Introduction & 1 & Orientation & $\begin{array}{l}\text { - Introducing the concept and application of the } \\
\text { strength based positive psychology program } \\
\text { (focused on the settings of archery game). } \\
\text { - Specifying the needs that participants want to } \\
\text { change through this program. } \\
\text { - Measure and assessment by using the questionnaire } \\
\text { (Optimism, Strength Knowledge, Strengh Use). }\end{array}$ & \begin{tabular}{|} 
- Specifying \\
participants' needs \\
- Increasing participants' \\
self awareness
\end{tabular} & \\
\hline \multirow[t]{2}{*}{$\begin{array}{l}\text { Cultivating } \\
\text { positive self }\end{array}$} & 2 & $\begin{array}{l}\text { Visualizing } \\
\text { positive self }\end{array}$ & $\begin{array}{l}\text { - Writing about three good things in my daily life, } \\
\text { training, and competition. } \\
\text { - Savoring the moment } \\
\text { - Thinking about what to do and setting a goal for } \\
\text { good thing to continue to happen in the future. } \\
\text { - Recognizing the strengths through positive } \\
\text { improvement. }\end{array}$ & $\begin{array}{c}\text { - Simplification of } \\
\text { thinking } \\
\text { - Developing strategies } \\
\text { for short, mid, long-term } \\
\text { goal achievement. }\end{array}$ & \multirow[t]{2}{*}{$\begin{array}{l}\text { Seligman et al. } \\
\text { (2005,2009) } \\
\text { King et al.(2000) } \\
\text { Gander et al.(2012) }\end{array}$} \\
\hline & 3 & $\begin{array}{l}\text { Fostering } \\
\text { positive } \\
\text { thinking }\end{array}$ & - Practicing gratitude by counting one’s blessing & $\begin{array}{l}\text { - Rehearsal of positive } \\
\text { statement (developing } \\
\text { positive self-talk) }\end{array}$ & \\
\hline \multirow{4}{*}{$\begin{array}{l}\text { Improving } \\
\text { strength } \\
\text { knowledge } \\
\text { and strength } \\
\text { use }\end{array}$} & 4 & $\begin{array}{l}\text { Strength } \\
\text { Knowledge }\end{array}$ & $\begin{array}{l}\text { - Finding a physical, technical, and psychological } \\
\text { strength as a archer. } \\
\text { - Remind the best performance and what strengths } \\
\text { were at the moment. } \\
\text { - Imagerying the strength of the best performance } \\
\text { with the specific situation. }\end{array}$ & $\begin{array}{l}\text { - Imagery the best } \\
\text { performance } \\
\text { Imagery the strength }\end{array}$ & Cook(1998) \\
\hline & 5 & $\begin{array}{l}\text { Strength } \\
\text { use(1) }\end{array}$ & $\begin{array}{l}\text { - Establishing the strength based strategy for } \\
\text { dealing with adverse. } \\
\text { - Writing what strength I used to overcome } \\
\text { adversity as an archer. } \\
\text { - Writing what was the strength I needed when I } \\
\text { failed. }\end{array}$ & - Improving strength use & $\begin{array}{l}\text { King et al.(2000) } \\
\text { King(2001) }\end{array}$ \\
\hline & 6 & $\begin{array}{l}\text { Strength } \\
\text { use(2) }\end{array}$ & $\begin{array}{l}\text { - Utilizing the strength in a various situations. } \\
\text { - Establishing behavioral strategies that can be used } \\
\text { in daily life, training, and competitions. }\end{array}$ & - Improving strength use & Green et al.(2006) \\
\hline & 7 & $\begin{array}{l}\text { Sharing and } \\
\text { supporting } \\
\text { the strength }\end{array}$ & $\begin{array}{l}\text { - Inform the strengths to family members and } \\
\text { receive support and feedback to improve mental } \\
\text { toughness. }\end{array}$ & $\begin{array}{l}\text { - Social support for } \\
\text { one's strength }\end{array}$ & $\begin{array}{l}\text { Seligman et al. } \\
(2005,2009)\end{array}$ \\
\hline Termination & 8 & $\begin{array}{l}\text { Establishing } \\
\text { action plan } \\
\text { for long-term } \\
\text { use of the } \\
\text { program }\end{array}$ & $\begin{array}{l}\text { - Establish an action strategy to implement and } \\
\text { sustain strength-based positive psychological } \\
\text { programs (goal setting). } \\
\text { Revise goals or plans set in the initial stage(if } \\
\text { necessary). } \\
\text { - Post measurement } \\
\text { - In-depth interviews }\end{array}$ & $\begin{array}{l}\text { - Establishing behavioral } \\
\text { strategies for continuous }\end{array}$ & $\begin{array}{l}\text { Sheldon et al. } \\
\text { (2002) }\end{array}$ \\
\hline
\end{tabular}

도구로 $J_{0}(2003)$ 가 한국어로 번안하고 $\operatorname{Kim}(2011)$ 이 활 용한 Scheier, Carver와 Bridges(1994)의 '삶의 경향성 평가지 (The revised Life Orientation Test: LOT-R)'를 사용하였다. 이 설문지에는 낙관성을 측정하는 긍정적 진 술문항 3개(예, 나는 언제나 내 미래에 대해서 낙관적이 다.)와 부정적 진술문항 3 개(예, 나는 나에게 좋은 일들이
일어날 것이라고 거의 기대하지 않는다)로 구성되어 있 다. 또한 나머지 4 개 문항은 참여자가 질문지의 의도를 파 악하지 못하도록 끼어넣은 문항(filter items)으로(예, 나 에게 있어 긴장을 푸는 것은 쉽다.) 채점에서 제외한다. 5 점 척도로 부정적 문항의 역점수 환산을 통해 총점은 6점 에서 30점의 범위를 갖으며, 내적 신뢰도는 .78로 나타났다. 


\section{4) 심층면담}

강점-기반 긍정심리프로그램 적용의 효과를 더욱 구체 적으로 알아보기 위하여 질적자료 수집 방법인 심층면담 을 실시하였다. 심층면담은 다른 사람들의 생생한 경험과 그 경험으로부터 만들어지는 의미를 이해하는 것에 관심 이 있어(van Manen, 1990), 연구자가 직접적으로 관찰 할 수 없는 상황에서 현상을 이해할 수 있는 중요한 도구 가 된다(Kim, 2016). 먼저 심층면담에서 활용할 질문을 스포츠심리학 박사 5 인의 전문가 회의를 통해 선정하고, 강점-기반 긍정심리프로그램에 참여한 양궁선수들에게 반구조화 심층면담을 진행하였다. 심층면담을 통해 양궁 선수들이 지각하는 프로그램 적용에 따른 인식변화 및 효 과를 알아보았다.

\section{연구절차}

본 연구는 양궁선수를 대상으로 하여 8주간의 강점-기 반 긍정심리프로그램 적용 효과를 검증하기 위해 양적 자 료로 사전, 사후에 설문지에 응답하도록 하였다. 원활한 설문을 위해 모든 설문은 익명으로 실시하였으며 응답자 가 편안함을 느낄 수 있는 공간에서 충분한 시간을 가지 고 응답하도록 하였다. 프로그램에 참여하지 않는 통제집 단은 가능한 프로그램 적용집단과 시간적으로 유사한 시 기에 설문에 응할 수 있도록 사전검사 이후 최소 6-8주간 의 기간을 두고 사후검사를 실시하도록 하였다. 또한 질 문지 측정을 통한 양적 자료의 수집과 더불어 프로그램의 적용을 통한 선수들의 다양한 변화를 알아보기 위하여 프로 그램 적용 후 선수들에게 개인 심층 면담을 실시하였다.

양궁선수를 위한 강점-기반 긍정심리프로그램은 Seligman, Ernst, Gillham, Reivich, \& Linkins(2009) 와 Seligman, Steen, Park, \& Peterson(2005)의 연구 및 인간의 강점 발견하기(Lopez, 2008), 긍정심리학 (Diener, E., \& Biswas-Diener, R., 2011)와 국내 대학 운동선수를 대상으로 한 긍정심리 개입 프로그램(Lee \& Shin, 2017)을 기반으로 프로그램을 구성하였다. 양궁 선수를 위한 강점-기반 긍정심리프로그램은 긍정 자아 향상과 강점인식 및 활용을 목표로 하였으며, 이에 적합 한 활동으로 구성하였다. 본 프로그램은 한 회기 당 약 40-60분씩 총 8회기로 구성하였으며, 1 주일에 한 회기씩
적용하였다. 참여자가 본 프로그램에 전념할 수 있도록 각 회기 전에 그 회기의 주제와 연관된 정보를 미리 제공 하여 충분한 시간을 가지고 생각할 수 있게 했다.

또한, 회기마다 실천 과제를 제시함으로써 참여자가 능동적 주체가 되어 프로그램을 이끌어 나가도록 구성하 였다. 1회기는 프로그램에 대한 참여자의 전반적 이해를 도와 참여자의 요구를 파악하고 사전 심리 검사를 진행하 도록 구성됐다. 2-3회기는 Seligman 등 $(2005,2009)$ 의 프로그램을 기반으로 참가자 내면의 긍정적 자원을 극대 화하고 긍정적 자기 인식을 통해 4회기에서 분명하고 확 실한 강점을 찾을 수 있도록 구성했다. 4-6회기에서는 인 간의 강점 발견하기(Lopez, 2008) 및 긍정심리학 (Diener, E., \& Biswas-Diener, R., 2011)의 강점활용 활동을 기반으로 강점활용에 초점을 두고 시합-훈련 상 황뿐 아니라 일상에서도 자신의 강점을 활용하고 발휘할 수 있도록 구성하였다. 7 회기에서는 사회적 지지를 통한 프로그램의 장기적 활용 토대를 만들고 8회기에서 구체 적인 지속 행동 전략 수립을 할 수 있도록 구성했다. 프로 그램의 내용은 〈Table 1 과 같다.

\section{자료분석}

연구대상자의 일반적 정보는 기술 통계를 이용하여 분 석하였으며, 피험자들의 사전, 사후에 나타나는 심리학 적 변인의 변화를 알아보기 위해 사전, 사후검사를 집단 내 요인 (within subject factor)으로 설정하여 혼합 모형 반복 측정 분산분석 (mixed model repeated measure ANOVAs; 2 X2 ANOVA)을 이용하여 분석하였다. 유의 한 차이가 확인된 주효과(main effect)를 분석하기 위한 사후검사(post hoc test)로 Boferroni correction을 사용 하였으며, 통계적 유의수준은 .05로 설정하였다.

심층면담을 통하여 수집된 질적자료는 질적연구방법 (Kim, 2016)과 선행연구를 참고하여 귀납적 내용분석을 실시하였다. 의미 분석을 통해 내용이 유사하거나 중복된 자료를 추출하여 영역을 범주화하였다. 분석된 자료의 적 절성 등에 대한 내용의 타당도를 확보하기 위하여 책임연 구자를 포함한 스포츠심리학 박사 5 인이 분석 자료를 재 검토하고 의견을 수렴하여 이를 결과에 반영하였다. 


\section{연구결과}

강점-기반 긍정심리프로그램 적용에 따른 심리적 변인의 변화

\section{강점인식}

8 주간의 강점-기반 긍정심리프로그램에 참여한 프로 그램 적용집단과 통제집단의 강점인식에 대한 변화를 분 석한 결과, 두 집단 모두 사전검사보다 사후검사에서 높 은 점수를 보인 것으로 나타나 검사 시기 간 유의한 차이 를 보인 것으로 나타났다 $(\mathrm{F}(1,18)=13.58, p<.05)$. 그러 나 프로그램 적용집단과 통제집단 간에 유의한 차이는 나 타나지 않았으며 $(p=.73)$, 검사시기와 집단 간 상호작용 역시 유의하지 않은 것으로 나타났다 $(p=.43)$ (Figure $1 \mathrm{~A})$.
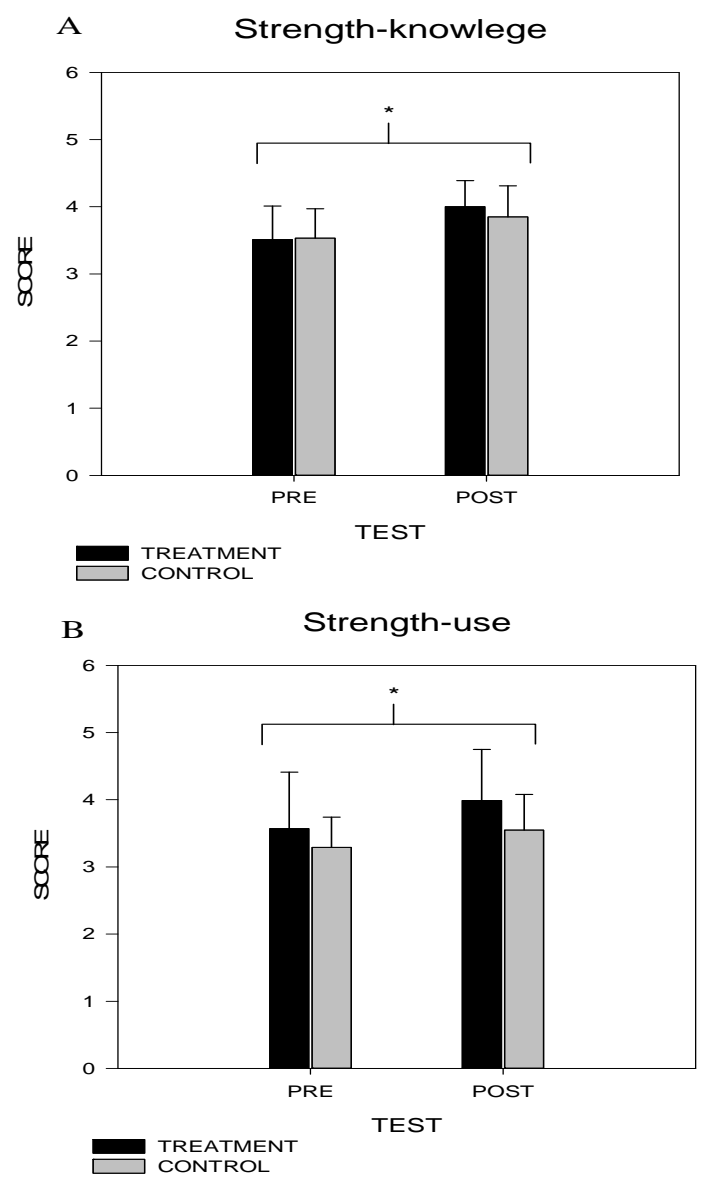

Fig. 1. Group differences in strength-knowledge(A) and strength-use(B)

\section{강점활용}

강점활용 또한 강점인식과 마찬가지로 프로그램 적용 집단과 통제 집단 모두 사전검사보다 사후검사에서 높은 점수를 보여 통계적으로 유의한 차이가 발견되었다 $(\mathrm{F}(1,18)=7.09, p<.05)$. 집단의 주효과 $(p=.19)$, 및 검 사시기와 집단 간의 상호작용 $(p=.52)$ 은 유의하지 않은 것으로 나타났다(Figure $1 \mathrm{~B})$.

\section{낙관성}

8주간의 프로그램에 참여한 프로그램 적용집단과 통 제집단의 낙관성을 질문지를 통해 사전, 사후로 측정하여 변화를 분석한 결과, 사전-사후 검사의 주효과는 유의하 지 않은 것으로 나타났다 $(\mathrm{F}(1,18)=4.31, p=.052)$. 그 러나 프로그램에 참여한 집단은 사전검사 $(\mathrm{M}=3.68$, $\mathrm{SD}=.86)$ 보다 사후검사 $(\mathrm{M}=4.05, \mathrm{SD}=.71)$ 에서 높은 점수를 나타냈으며 통제집단 역시 사전검사 $(\mathrm{M}=3.53$, $\mathrm{SD}=.33)$ 보다 사후검사 $(\mathrm{M}=3.61, \mathrm{SD}=.43)$ 에서 소폭 상승하거나 거의 변화가 없는 상태를 보여주어 통계적 유 의 수준 $(p=.05)$ 에 접근하는 결과를 나타냈다. 집단의 주효과 $(p=.21)$ 역시 유의하지 않는 것으로 나타나 프로 그램 적용집단과 통제집단 간 차이는 발견되지 않았으며 집단과 검사 시기 간 상호작용 $(p=.20)$ 또한 유의하지 않 은 것으로 나타났다(Figure 2).

\section{Optimism}

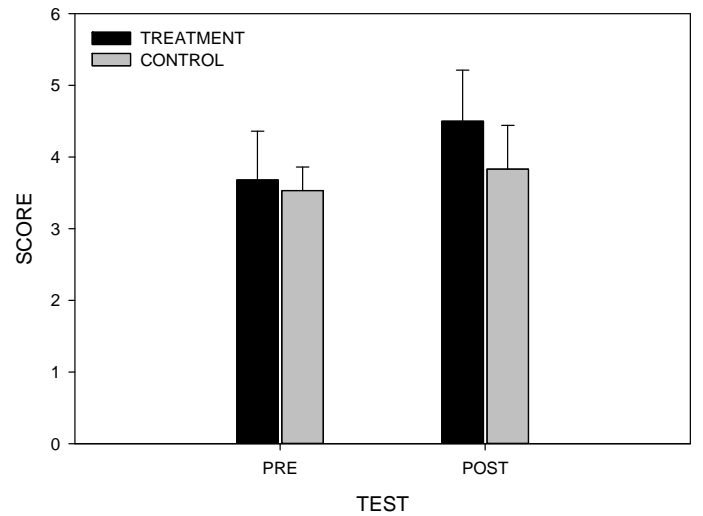

Fig. 2. Group difference in optimism 


\section{강점-기반 긍정심리프로그램 적용에 따른 선수들이 지각하는 변화}

이 연구에서 적용한 강점-기반 긍정심리프로그램의 적 용 효과를 보다 폭넓은 관점에서 알아보고자 프로그램에 참여한 선수들을 대상으로 심층면담을 실시하였다. 심층 면담에서 선수들이 지각한 프로그램 적용 후의 변화는 긍 정적 생각과 대처, 자신감과 자존감 향상으로 나타났다.

\section{긍정적 생각과 대처}

강점-기반 긍정심리프로그램에 참여했던 양궁선수들 은 훈련이나 평소 생활에서 긍정적인 생각을 더 많이 하 게 되었다고 언급하였다. 또한 훈련이나 경기에서 부정적 으로 생각하게 되는 상황에서 긍정적으로 대처할 수 있게 되었다고 진술하여 평소 생활면에서 양궁 훈련 및 경기에 서 긍정적 생각으로 대처할 수 있는 능력을 키운 것으로 생각된다.

"평소에 감사하다고 느끼지 못했던 소소한 일들을 긍정적 인 시각으로 바라보게 되었고, 그게 좋은 습관으로 만들어진 것 같아요..(중략)..나는 내가 대체적으로 긍정적인 생각을 많이 한다고 생각했었는데, 첫날 설문 조사를 하면서 내 자 신에 대한 믿음도 적고...(중략)... 그렇게 긍정적인 생각을 많이 하지 않는 걸 깨달았어요. 프로그램에 참여하면서 나의 강점이 이제는 바로 생각이 나고, 평소 생활에서 생각하는 거나 운동할 때 긍정적으로 바뀐 나를 느껴요." (선수 B)

"프로그램을 하면서 '나'라는 존재에 대해 많이 생각하고, 조금 더 긍정적인 내가 될 수 있다는 걸 깨달았어요. 나도 모르게 훈련이나 경기에서 부정적으로 생각하게 되는 상황 이 있는데, 이제는 그럴 때에 긍정적으로 대처할 수 있어 요." (선수 J)

"내가 잘하는 강점을 양궁에서 쓰는 방법을 알고 나서 경기 에서 되게 안 좋았던 상황에서 대처하지 못한 게 생각나서 조 금 답답했는데..(중략)...이제는 훈련에서 기록 재거나 할 때 내가 잘하는 걸 더 생각하면서 대처하는 연습을 하고 있어서 경기에서도 안 좋은 상황에서 써볼 생각이에요." (선수 F)

"프로그램을 하면서 긍정적으로 생각을 하고 강점을 생각 하면서 기분이 업되고, 평소에 그리고 훈련할 때도 나쁜 말 을 들어도 커버할 수 있을 것 같고, 단점을 긍정적으로 보완 해아겠다고 마음을 먹었어요." (선수 H)

\section{자신감과 자존감 향상}

강점-기반 긍정심리프로그램에 참여했던 선수들은 자 신의 강점을 찾고 활용하게 되면서 자신에 대한 믿음과 자신을 존중하는 자존감이 향상되었음을 느꼈다고 진술 하였다.

"양궁선수로서 나의 강점은 바람이 불더라도 자신있게 나 를 믿고 쏘고, 경기가 잘 풀리지 않더라도 포기하지 않고 내 가 할 것만 생각하고 쏘는 끈기와 집중력이에요. 이런 나의 강점을 찾기 시작하면서 나도 잘 몰랐던, 생각해 보지 않았 던 것들을 생각하며 자신감, 자존감이 올라가는 듯한 느낌이 들었어요." (선수 A)

"나 자신에 대해서 모르는 게 많았는데, 내가 잘하는 걸 찾 으면서 내가 좀 더 채워지는 것 같아서 좋았어요. 평소에는 안되는 것을 고치려고 단점을 많이 생각했는데, 이 프로그램 을 하면서 긴 시간 훈련에도 최선을 다해 끝까지 노력하는 점, 실수 직후에도 침착하게 다음 슈팅을 하는 점 이러한 강점을 생각해보고 기록 잴 때 내가 잘하는 것을 생각하니 내 자신을 더 믿게 되었어요. 그리고 내가 외면했던 마음 속 문제를 마 주한 것 같아 한결 편해졌고 날마다 나를 칭찬해주니까 자존 감이 조금씩 높아지는 것 같아서 좋았어요." (선수 D)

"선수로서 긍정적인 성격을 가지고 있지만 자존감과 자신 감은 낮은 편이었어요. 남들이 나를 어떻게 생각할 까? 남들 은 어떻게 쏘고 있지? 이렇게 다른 사람들을 자꾸 신경썼는 데, 그치만 이번 프로그램을 하면서 나에게 집중하고, 나의 장점을 생각하면서 자신감과 자존감을 되찾을 수 있어서 너 무 좋았어요." (선수 $\mathrm{G}$ )

"나의 강점 같은 걸 모르고 신경 쓴 적도 없었는데, 이런 프로그램을 하면서 내 장점을 찾아보려고 하고 있어요. 경기 를 할 때 자신감 있는 걸음걸이와 상대선수가 나의 감정을 알아채지 못하게 포커페이스를 하는 것이 제 강점이더라구 요. 이렇게 강점을 찾다 보니까 뭔가 잘 될 것 같고,,,내 자 신에 대한 믿음이 커지는 것 같아요." (선수 E)

이와 같이 자신의 약점 보다는 강점에 주목하고 활용 하는 강점-기반 긍정심리프로그램 적용은 선수들의 자신 감과 자존감 그리고 생활과 훈련 및 경기에서의 긍정적인 생각과 대처 등 선수들에게 긍정적인 영향을 미친 것으로 나타났다. 


\section{논의}

본 연구는 강점-기반 긍정심리프로그램을 현장의 양궁선 수들에게 적용하고 그 효과를 검증하는데 목적이 있었다.

먼저, 본 연구에서 8주간의 강점-기반 긍정심리프로그 램에 참여한 집단과 통제집단의 강점인식 수준을 비교한 결과 두 집단 간 강점인식 수준의 차이는 통계적으로 유 의하지 않은 것으로 나타났다. 하지만 집단 내 수준에서 사전-사후의 강점인식 수준은 프로그램 참여집단과 통제 집단 모두 사전검사와 비교하여 사후검사에서 유의하게 높아진 것으로 나타났다. 둘째, 프로그램 참여집단과 통 제집단의 강점활용 수준의 변화를 검증한 결과 두 집단 간 사전-사후의 변화량은 통계적으로 차이가 나지 않는 것으로 나타났다. 강점활용과 마찬가지로 집단-내 수준 에서 프로그램 참여 집단과 통제 집단 모두 강점활용 수 준이 유의하게 증가한 것으로 확인되었다. 셋째, 프로그 램 참여집단과 통제집단의 낙관성 수준의 변화는 집단간, 집단-내 수준에서 모두 유의한 차이가 나타나지 않은 것으로 확인되었다.

본 연구에서 8주간 강점-기반 긍정심리프로그램에 참 여한 집단의 강점인식 및 활용은 사전검사에서 보다 사후 검사에서 더 높은 수준으로 나타났으나 전체적인 사전사후 변화량은 통제 집단과 차이가 없는 것으로 나타났 다. 이러한 결과는 강점 기반 프로그램을 적용한 국외의 선행연구에서 보고된 것과 같이 강점인식 및 강점활용 프 로그램에 참여한 집단의 중재 개입 직후 종속측정치에는 프로그램 사전-사후 간 차이가 없는 것으로 나타나 본 연 구의 결과와 유사한 결과를 보이고 있다(Seligman et al., 2005). 하지만 6개월 이후 강점인식 프로그램 집단 보다 강점활용 집단에서 더 높은 삶의 만족도, 행복, 그리 고 긍정 정서를 보였다. Seligman 등(2005)의 연구에서 밝혀졌듯 강점-기반 긍정심리 중재프로그램의 적용을 통 한 변화는 단속적-일회적 효과를 기대하긴 힘들다. 강점 은 단순히 인식하고 있는 것만으로는 행복감이나 긍정적 인 정서에 장기적으로 영향을 미치지 못하고, 긍정심리 개입프로그램을 통해 적극적, 장기적으로 활용했을 때 삶 의 만족도나 행복감의 긍정적·장기적 성장을 기대할 수 있다는 점에서 프로그램 활용에 대해 시사하는 바가 크 다. 비록 통계적 분석에서 나타나지는 않았지만 심층면담
과정에서 프로그램에 참여했던 모든 선수들이 문제점을 지적하고 수정하는 과정보다 자신의 강점을 찾아가고 활 용하는 방법을 배우는 과정에서 자신에 대해 좀 더 긍정 적인 시각으로 바라보게 됐다는 점은 일반 대학생을 대상 으로 강점 개입을 적용한 결과 긍정정서가 향상되었다는 국내의 연구결과와 일치한다(Kim \& Kwon, 2013).

본 연구에서는 프로그램 적용을 통해 운동선수들이 단 순히 자신의 강점을 확인하고 사용하는 것을 권하기 보다 인식하지 못하고 있던 자신의 강점을 개발하여 주어진 환 경에서 이 강점의 효과를 극대화할 수 있는 방안을 찾고 자 정교한 접근을 시도하였다. 강점-기반 접근의 일반적 방식은 '확인 및 사용'의 접근법으로 정형화된 강점 측정 도구를 통해 강점의 특성이나 재능을 확인하고 내담자와 논의하여 생활 속에서 이러한 강점을 자주 활용할 수 있 도록 하는 방식이다(Buckingham \& Clifton, 2001). 하 지만, Biswas-Diener, Kashdan, \& Minhas(2011)는 '강점 개발'은 운동선수 자신의 강점을 더 잘 이해할 수 있 고 이를 더 큰 효과로 구현하는 방법을 찾아 낼 수 있다고 주장하였다. 이러한 관점을 기반으로 본 연구에서는 양궁 선수들이 자신만의 특징적 강점을 개발하도록 돕고 잠재 적으로 강력한 스포츠 자신감을 형성하는 것을 목표로 하 였다. 따라서, 본 연구에서 적용한 프로그램은 운동선수 들이 경기상황에 따른 자신의 강점을 개발하고 이를 활용 하여 효과를 극대화 할 수 있도록 프로그램을 구성하였으 므로, 삶의 질이나 행복감과 같은 심리 변인보다는 강점 인식 및 강점활용과 낙관성의 변화를 검증하였다.

본 연구에서는 프로그램 참여집단과 통제집단 간 종속 측정치의 통계적 차이점을 발견하지 못하였다. 그 이유는 크게 두 가지로 해석된다. 첫째, 본 연구는 국내 대학 및 실업 선수들을 대상으로 하고 있다. 국내 엘리트 양궁선 수들의 정신력과 기량은 세계적인 수준으로 기술의 연속 체에서 천장 수준(ceiling level)에 있다고 볼 수 있다. 이 러한 단계에서 눈에 띄는 프로그램의 중재 효과를 나타내 기엔 제한이 있다고 판단된다. 또한, 사전연구에서 정서 적행동적 결손으로 인해 긍정적 활동과 관련된 이점을 극대화하기 힘들기 때문에 긍정심리 개입프로그램의 효 과는 기대하기 힘들 것이라는 우려와는 반대로 긍정심리 개입프로그램에 참여한 우울증 환자(Fava, Rafanelli, Cazzaro, Conti, \& Grandi, 1998), 외상성 뇌 손상 환 
자(Bedard et al., 2003), 청소년(Forbes \& Dahl, 2005), 군인 (Steenkamp, Nash, \& Litz, 2013)들은 일 반인 보다 더 높은 수준의 웰빙과 우울 완화 및 우울 재발 방지 효과를 확인 할 수 있었던 점도 일반인 보다 개선될 수 있는 폭이 더 넓었기 때문에 가능한 것으로 해석된다 (Fava et al., 1998; Seligman, Rashid, \& Parks, 2006). 따라서 추후 연구에서는 종목과 기술 수준, 연령 에 따라 프로그램 적용에 대한 효과의 차이를 검증하고 이를 통해 더욱 효과적인 프로그램을 개발할 수 있을 것 이라 생각된다. 둘째, 자기 보고식 설문지가 가진 외생변 수에 대한 취약점 (예: 주관적, 측정시기에 대하 민감성 등)으로 인한 것으로 해석할 수 있다. 프로그램 적용 시기 는 양궁 경기가 없는 8주간 적용되었으며, 사후검사는 전 국체육대회 직전에 측정하였다. 엘리트 운동선수들은 경 기 전 양질의 훈련뿐만 아니라 자신감, 집중력을 높이기 위한 심리적 준비를 하는 것으로 나타났다(Williams \& Krane, 2001). 따라서 프로그램을 적용한 양궁선수들 뿐만 아니라 통제집단의 양궁선수들도 시합을 위한 심리 적 준비를 하여 사후검사에서의 심리 수준이 향상된 것으 로 생각된다. 또한 경기 불안 관련 선행연구에서는 경기 전·중·후 경쟁 불안 상태의 변화를 측정하기 위해 자기보 고식 설문지와 불안상태의 객관적 척도가 될 수 있는 세 타파와 알파파의 좌·우뇌 비대칭 점수를 측정하였다. 연 구결과에서 대뇌반구 비대칭 점수는 시기별로 차이가 나 타났으나 상태 불안 질문지의 응답 수준은 시기별로 차이 가 나타나지 않았다(Lee et al, 2016). 종합하자면 프로 그램 적용에 대한 효과 검증을 위해서는 다각적인 연구방 법의 적용과 결과에 영향을 미칠 수 있는 외생변수에 대 한 세심한 고려가 요구된다고 할 수 있다.

다수의 연구에서 개입프로그램 종료 후에도 계속해서 그 프로그램을 활용하고 행복 증진 전략을 수립하고 연습 하기 위해 고군분투하는 것은 장기적으로 웰빙 수준이 향 상되는 것으로 나타났다(Lyubomirsky, Dickerhoof, Boehm, \& Sheldon, 2011; Seligman et al., 2005). 따 라서, 본 연구에서 적용된 강점-기반 긍정심리프로그램 에서는 참가자로 하여금 자신의 긍정적 전략을 계속해서 기록하고 규칙적으로 활용하여 이러한 전략들을 자신의 삶에 녹아들게 하여 습관이 될 수 있도록 설계하였다. 한 참여자가 여러 가지 긍정심리 활동을 하게 하는 “샷건”접
근 방식은 한 가지 긍정심리 활동에 집중하는 것보다 더 효율적인 것으로 밝혀졌다(Fordyce, 1977; Seligman et al., 2005).

비록 스포츠심리학 관련 연구에서 강점-기반 접근에 대 해 다루고 있는 문헌을 찾기는 쉽지 않지만, 전문가들이 현 장에서 강점-기반 중재기법을 전혀 적용하고 있지 않고 있 다는 의미는 아니다. Scheel, Davis와 Henderson(2012) 의 주장과 같이 비록 장애 치료를 목적으로 한 인지 행동 적 체계에서 중재가 진행이 되고 있다 하더라도 강화와 지지와 같은 긍정적 과정을 제공할 수 있다. 그럼에도 불 구하고 기존 연구들에서 강점-기반 접근의 활용에 대한 명확성은 부족한 실정이다. 따라서 내담자의 강점을 최적 화하는 방법에 대한 명확한 합의가 이루어진다면 강점기반 접근을 활용하려는 전문가들에게 큰 도움이 될 것으 로 판단된다(Scheel et al., 2012; Ludlam et al., 2016). 이에 본 연구에서는 다양한 활동으로 회기를 구성 한 프로그램을 적용하였다. 또한, 참여자 개인의 사고방식 ·문화적 배경, 자신의 인생에서 가장 중요하게 여기는 가 치 등은 개인의 행복 추구를 뒷받침해주는 필수적 정보들 로 참여자의 포괄적 정보보다 긍정심리 개입프로그램 적 용에 더 많은 도움을 준다고 보고되어(Lyubomirsky et al., 2011), 프로그램 초기 단계에서 개인상담을 통해 개 인의 특성과 프로그램 참여를 통해 얻고자 하는 목적, 개 인의 요구 등을 파악하여 프로그램을 참가자의 요구와 개 인의 강점에 중점을 두고 프로그램을 적용하여 프로그램 에 대한 만족도를 향상시킬 수 있었다.

\section{결론 및 제언}

본 연구는 양궁선수들을 대상으로 강점-기반 긍정심리 프로그램을 적용하고 그 효과를 검증하는 것을 목적으로 하였다. 8주간의 강점-기반 긍정심리프로그램을 적용한 후 프로그램 적용집단과 통제집단의 심리적 변인의 변화 를 검증하였다. 그 결과 다음과 같은 결론을 도출하였다. 첫째, 8주간 강점-기반 긍정심리프로그램에 참여한 양궁 선수들의 강점인식 및 강점활용과 낙관성 수준은 통제 집 단과 비교하여 통계적으로 유의한 차이가 나타나지 않았 다. 둘째, 심층면담 결과 선수들은 강점-기반 긍정심리프 
로그램에 참여하면서 자신의 약점 보다는 강점에 주목하 고 활용하여 긍정적인 생각과 대처뿐만 아니라 자신감과 자존감이 향상되는 긍정적인 변화를 지각하는 것으로 나 타났다.

본 연구에서의 결과를 토대로 후속 연구에서 고려되거 나 해결되어야 할 과제를 제언하면 다음과 같다. 먼저 본 연구에서는 강점-기반 긍정심리프로그램 적용의 효과를 검증하고자 낙관성, 강점인식 및 강점활용 등의 심리적 변인의 변화를 검증하였다. 하지만, 프로그램 적용 이후 선수들의 수행 데이터나 심리 생리적 변화와 같은 객관적 변수들을 고려하지 못한 제한이 있다. 따라서, 추후 연구 에서는 뇌 이미지 데이터와 수행 데이터의 변화를 동시에 수집하고 분석할 수 있는 기법을 활용하여 심리 생리적 변화와 함께 운동 수행 (경기력)의 변화를 검증한다면 운 동선수를 대상으로 한 심리 프로그램의 궁극적인 목표인 경기력 향상에 도움이 되는 프로그램의 검증이 될 것이라 판단된다.

마지막으로 본 연구에서는 프로그램 적용 효과 검증을 위하여 사전과 사후 질문지를 활용한 측정을 수행하였다. 따라서 프로그램 종료 후 그 효과가 얼마나 지속되는지에 대한 정보는 제공할 수 없는 제한점이 있다. 후속연구에 서는 추후 측정을 통하여 프로그램 적용 효과의 지속성을 검증한다면 프로그램의 타당성을 더욱 높일 수 있을 것으 로 생각된다.

\section{참 고 문 헌}

Bedard, M., Felteau, M., Mazmanian, D., Fedyk, K., Klein, R., Richardson, J., ... \& Minthorn-Biggs, M. B. (2003). Pilot evaluation of a mindfulness-based intervention to improve quality of life among individuals who sustained traumatic brain injuries. Disability and Rehabilitation, 25(13), 722-731.

Bolier, L., Haverman, M., Westerhof, G. J., Riper, H., Smit, F., \& Bohlmeijer, E. (2013). Positive psychology interventions: a meta-analysis of randomized controlled studies. BMC public health, 13(1), 119.

Buckingham, M., \& Clifton, D. O. (2001). Now, discover your strengths. New York, NY: The Free Press.

Choi S, H., \& Song Y, K. (2017). The effect of the Performance psychological skill strategy in the effectiveness of psychological skill training on the archery player in middle school. The Korean Journal of physical Education, 56(3), 99-114.

Compton, W.C. (2005). An introduction to positive psychology. Belmont, CA: Wadsworth.

Cravens, K. S., Oliver, E. G., \& Stewart, J. S. (2010). Can a positive approach to performance evaluation help accomplish your goals? Business Horizons, 53(3), 269-279.

Diener, E., \& Biswas-Diener, R. (2011). Happiness: Unlocking the mysteries of psychological wealth. Victoria, Australia: John Wiley \& Sons.

Fava, G. A., Rafanelli, C., Cazzaro, M., Conti, S., \& Grandi, S. (1998). Well-being therapy. A novel psychotherapeutic approach for residual symptoms of affective disorders. Psychological medicine, 28(2), 475-480.

Forbes, E. E., \& Dahl, R. E. (2005). Neural systems of positive affect: Relevance to understanding child and adolescent depression? Development and psychopathology, 17(3), 827.

Fordyce, M. W. (1977). Development of a program to increase personal happiness. Journal of Counseling Psychology, 24(6), 511.

Gander, F., Proyer, R. T., Ruch, W., \& Wyss, T. (2013). Strength-based positive interventions: Further evidence for their potential in enhancing well-being and alleviating depression. Journal of Happiness Studies, 14(4), 1241-1259.

Golby, J., \& Sheard, M. (2004). Mental toughness and hardiness at different levels of rugby league. Personality and individual differences, 37(5), 933-942.

Gordon, S. (2012). Strengths based approaches to developing Mental Toughness: Team and individual. International Coaching Psychology Review, 7, 210 - 222.

Gould, D., Dieffenbach, K., \& Moffett, A. (2002). Psychological characteristics and their development in Olympic champions. Journal of applied sport psychology, 14(3), 172-204.

Govindji, R., \& Linley, P. A. (2007). Strengths use, self-concordance and well-being: Implications for strengths coaching and coaching psychologists. International Coaching Psychology Review, 2(2), 143-153.

Green, L. S., Oades, L. G., \& Grant, A. M. (2006). Cognitive-behavioral, solution-focused life coaching: Enhancing goal striving, well-being, and hope, The Journal of Positive Psychology, 1(3), 142-149. 
Han, M. W. (2012). The effects of PST on psychological variables and performance of a female archer showing learned helplessness phenomena: a case study. Korea Journal of Sport Science, 23(4), 845-857.

Jo, H. N. (2003). The relationship between optimism and interpersonal schemes, Unpublished master dissertation. Ewha Women's University.

Kaiser, R. B., \& White, R. P. (2009). Debunking an unbalanced approach to development. Leadership in Action, 28(5), 9-12.

Kim, B. H., \& Yang, C. H. (2010). The effect of psychological skills training in the archery filed. Korea Journal of Sport Science, 21(4), 1534-1545.

Kim, D. H., \& Oh, G. M. (2015). The Relationship between Emotion and Emotion Regulation and Performance in Archery Athletes. Korean Society of Sport Psychology, 26(4), 31-46.

Kim, E. J. (2011). The relationship between optimism and teacher-student relationship perceived by elementary students. Unpublished master dissertation. Korea University.

Kim, J. Y., \& Kwon, S. M. (2013). The influence of character strengths on mental health. Korean Journal of Clinical Psychology, 32(4), 783-802.

Kim, Y. C. (2016). Qualitative Research Methods(3rd ed.). Paju: Academypress.

King, L. A. (2001). The health benefits of writing about life goals. Personality and Social Psychology Bulletin, 27(7), 798-807.

King, L. A., \& Miner, K. N. (2000). Writing about the perceived benefits of traumatic events: Implications for physical health. Personality and Social Psychology Bulletin, 26(2), 220-230.

Laschinger, H. K. S., \& Fida, R. (2014). New nurses burnout and workplace wellbeing: The influence of authentic leadership and psychological capital. Burnout Research, 1(1), 19-28.

Layous, K., Chancellor, J., Lyubomirsky, S., Wang, L., \& Doraiswamy, P. M. (2011). Delivering happiness: Translating positive psychology intervention research for treating major and minor depressive disorders. The Journal of Alternative and Complementary Medicine, 17(8), 675-683.

Lee, H. W., \& Shin, J. T. (2017). The effect of positive psychological intervention program on mood state, self-esteem and happiness of university student athletes: Exploratory studies. Korean Journal of Sport Science, 28(1), 1020-1033

Lee, G. S., Kwon, M. G., Yeo, W, G., \& Kim, J. G.(2016). Changes in frontal brain asymmetry before and after swimming competition. Journal of Korean Physical Education and Sports for Girls and Women. 30(4), 291-302.

Lee, S. G., Kim, E. S., \& Kim, S. O. (2009). The Qualitative Analysis on Imagery Trait of Elite Archers. Korean Society of Sport Psychology, 20(30), 155-166.

Linley, P. A., Joseph, S., Harrington, S., \& Wood, A. M. (2006). Positive psychology: Past, present, and (possible) future. The Journal of Positive Psychology, 1(1), 3-16.

Lopez, S. J. (2008). Positive psychology: Exploring the best in people, Vol 1: Discovering human strengths. Praeger Publishers/Greenwood Publishing Group.

Ludlam, K. E., Butt, J., Bawden, M., Lindsay, P., \& Maynard, I. W. (2016). A strengths-based consultancy approach in elite sport: Exploring super-strengths. Journal of Applied Sport Psychology, 28(2), 216-233.

Lyubomirsky, S., Dickerhoof, R., Boehm, J. K., \& Sheldon, K. M. (2011). Becoming happier takes both a will and a proper way: an experimental longitudinal intervention to boost well-being. Emotion, 11(2), 391.

Moon, H. S., \& Park, J. S. (2008). The Relationship between Archers' Self management and Self-confidence. Korean Society of Sport Psychology, 19(1), 19-32.

Noble, D. N., Perkins, K., \& Fatout, M. (2000). On being a strength coach: Child welfare and the strengths model. Child and Adolescent Social Work Journal, 17(2), 141-153.

Ouweneel, E., Le Blanc, P. M., \& Schaufeli, W. B. (2013). Do-it-yourself: An online positive psychology intervention to promote positive emotions, self-efficacy, and engagement at work. Career Development International, 18(2), 173-195.

Park, B. K., \& Lee, H. K. (2012). Validation of the Korean Version of Strengths Use Scale (K-SUS). Korean Journal of Psychology: General, 31(3), 599-616.

Sarkar, M. \& Fletcher, D. (2013). How should we measure psychological resilience in sport performers? Measurement in Physical Education and Exercise Science, 17(4): 264-280

Scheel,M. J., Davis, C. K.,\&Henderson, J.D. (2012). Therapist use of client strengths:Aqualitative study of positive processes. The Counseling Psychologist, 41, 392 - 427.

Scheier, M. F., Carver, C. S., \& Bridges, M. W. (1994). Distinguishing optimism from neuroticism (and trait anxiety, self-mastery, and self-esteem): a reevaluation of the Life Orientation Test. Journal of personality and social psychology, 67(6), 1063. 
Seligman M.E.P., Csikszentmihalyi M. (2014) Positive Psychology: An Introduction. In: Flow and the Foundations of Positive Psychology. Springer, Dordrecht

Seligman, M. E., Ernst, R. M., Gillham, J., Reivich, K., \& Linkins, M. (2009). Positive education: Positive psychology and classroom interventions. Oxford review of education, 35(3), 293-311.

Seligman, M. E., Rashid, T., \& Parks, A. C. (2006). Positive psychotherapy. American psychologist, 61(8), 774.

Seligman, M. E., Steen, T. A., Park, N., \& Peterson, C. (2005). Positive psychology progress: empirical validation of interventions. American psychologist, 60(5), 410.

Sharp, L. A., Hodge, K., \& Danish, S. (2014). Sport psychology consulting at elite sport competitions. Sport, Exercise, and Performance Psychology, 3(2), 75.

Stander, F. W., Mostert, K., \& De Beer, L. T. (2014). Organisational and individual strengths use as predictors of engagement and productivity. Journal of Psychology in Africa, 24(5), 403-409.

Stander, F. W., De Beer, L. T., \& Stander, M. W. (2017). A strength-based approach to athlete engagement: an exploratory study. South African Journal for Research in Sport, Physical Education and Recreation, 39(1), 165-175.
Steenkamp, M. M., Nash, W. P., \& Litz, B. T. (2013). Post-traumatic stress disorder: Review of the Comprehensive Soldier Fitness program. American Journal of Preventive Medicine, 44(5), 507-512.

Van Manen, M. (1990). Researching lived experience: human science for an action sensitive pedagogy. Althouse press, London, ON.

Weston, N. J. V., Greenlees, I. A., \& Thelwell, R. C. (2011). Athlete perceptions of the impacts of performance profiling. International Journal of Sport and Exercise Psychology, 9, $173-188$.

Weston, N., Greenlees, I., \& Thelwell, R. (2013). Areview of Butler and Hardy's (1992) performance profiling procedure within sport. International Review of Sport and Exercise Psychology, $6,1-21$.

Williams, J. M., \& Krane, V. (2001). Psychological characteristics of peak performance. In J. M. Williams (Ed). Applied Sport Psychology: Personal growth to peak performance(4th ed., pp. 137-147). Mountain view, CA: Mayfield.

Yun, Y. K., Kim, W, B., \& Lim, T. H. (2006). Analytic Hierarchy Process to examine factors influencing sports performance. Korean Society of Sport Psychology, 17(1), 1-12. 


\section{양궁선수들을 위한 강점-기반 긍정심리프로그램의 적용 \\ 김영숙 ${ }^{1}$, 박인천 ${ }^{2}$ \\ 1한국스포츠정책과학원 선임연구위원 \\ 2한국스포츠정책과학원 초빙연구원}

[목적〕 본 연구는 양궁선수들을 위한 강점-기반 긍정심리프로그램을 적용하고 그 효과를 검증하는 것을 목 적으로 하였다. [방법) 실업 양궁선수 20 명이 연구에 참여하였고, 10 명의 양궁선수가 8 주간의 강점-기반 긍 정심리프로그램에 참여한 적용집단과 다른 10 명의 선수들을 통제집단으로 구성하였다. 프로그램 적용집단과 통제집단의 심리적 변인의 변화를 검증하기 위하여 프로그램 적용 사전과 사후에 강점인식 및 강점활용과 낙 관성을 측정하였으며, 자료는 반복측정 분산분석을 활용하여 검증하였다. 또한 프로그램을 적용한 선수들을 대상으로 개인별 심층면담을 실시하여 질적으로 그 효과를 알아보았다. [결과) 첫째, 강점에 기반을 둔 긍정심 리프로그램을 적용한 집단은 통제집단과 낙관성, 강점인식 및 강점활용 등 종속측정치에서 유의한 차이가 발 견되지 않았다. 둘째, 사후검사에서 프로그램 적용집단과 통제집단 모두 사전검사보다 강점인식 및 강점활용 과 낙관성 수준이 향상되었다. 셋째, 심층면담 결과에서 프로그램에 참여했던 선수들은 자신의 강점을 찾고 활용하는 과정을 통해 긍정적인 생각과 대처를 하게 되었으며, 자신감과 자존감이 향상된 것으로 나타났다. (결론) 이러한 연구의 결과를 기반으로 양궁 뿐만 아니라 다른 종목의 선수들에게 강점-기반 긍정심리프로그 램이 적용된다면 경기에서 강점에 집중하여 경기력에 도움이 될 것으로 예상된다.

주요어: 양궁, 강점, 긍정심리, 강점인식, 강점활용 